\title{
Treatment of Chalazian: a Comparative Cross-sectional Study
}

${ }^{*}$ Binita Bhattarai ${ }^{1}$, Koshal Shrestha ${ }^{1}$, Sushila Patel ${ }^{2}$, Laxmi Devi Manandhar ${ }^{1}$, Rosy Karki ${ }^{3}$, Nanda Gurung ${ }^{4}$

Authors Info:

${ }^{1}$ Department of Oculoplasty, Lumbini Eye Institute and Research Center, Bhairahawa, Nepal.

${ }^{2}$ Department of Cornea, Lumbini Eye Institute and Research Center, Bhairahawa, Nepal.

${ }^{3}$ Tilotamma Eye Hospital, Butwal 8, Nepal.

${ }^{4}$ Department of glaucoma, Lumbini

Eye Institute and Research Center,

Bhairahawa

* Corresponding Author:

Dr. Binita Bhattarai, Oculoplasty surgeon,

Contact No: 9857030190

E mail: bhattaraibinita@hotmail.com

Disclaimer:

Conflict of Interest: None

Source of Support: None

Copyright $\odot 2019$ by author(s), licensed under the Creative Commons Attribution International License 4.0.

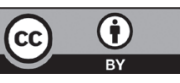

\section{ABSTRACT:}

Introduction: Chalazion is a common eyelid margin disorder manifesting as granulomatous inflammation associated with meibomian gland lipids. There are three methods of treating chalazian: Intralesional Triamcinolone Acetonide (0.1-0.3 $\mathrm{ml}$ of $40 \mathrm{mg} / \mathrm{ml}$ ), Incision and Curettage and Conservative Treatment (hot compression +lid hygiene + antibiotic ointment).

Methods: Patients with chalazian presenting to Outpatient Department (OPD) of Lumbini Eye Institute and Reserch Center (LEIRC) from 15 March 2017 to 15 July 2017 were included in the study. They underwent any of the three procedures (Conservative Treatment or Triamcinolone Acetonide Injection or Incision and Curettage) according to their choice. We compared all three methods of treatment of chalazion on follow up visit at 2 weeks, which was done to determine effectiveness in terms of reduction of size or complete resolution of the chalazia.

Results: Out of 112 patients enrolled in the study 65(58\%) were females and $47(42 \%)$ were male with a male: female ratio of (0.7:1). Mean age of involvement was 25.7years (SD 10.3). At 2 weeks follow up there was complete resolution in incision and curettage (I and C) group $77 \%(41 / 53)$ and in Triamcinolone Acetonide (TA) injection group $63 \%(20 / 32)$. Pearson's correlations showed that I and C were superior to any other forms of intervention for any size of chalazian followed by intralesional injection of TA.

Conclusion: Incision and Curettage remained the best choice for treatment of chalazionfollowed by triamcinolone acetonide injection but may need multiple injections.

Keywords: Chalazion, Intralesional Triamcinolone Acteonide, Incision and Curettage, Meibomian Gland.

\section{Article Info}

Received: October 19, 2019

Accepted: December 7, 2019

Published Online: December 12, 2019

How to cite this article in Vancouver Style?

Bhattarai B, Shrestha K, Patel S, Manandhar LD, Karki R, Gurung N. Treatment of Chalazian: A comparative Cross-sectional Study. Europasian J Med Sci 2019;1(1):59. https://doi.org/10.46405/ejms.v1i1.3

\section{Access this article online}

Publisher Note:

The Europasian Journal of Medical Sciences (EJMS) is an official Journal of Nirvana Psychosocial Care Center \& Ressearch Institute www.nirvanapscc.com. The Journal as well as publisher remain neutral with regards to any jurisdictional claims in any published articles, its contents and the institutional affiliations of the authors.
Quick Response (QR) Code

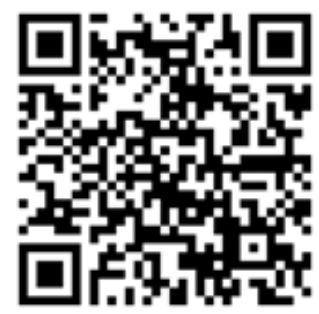

Scan Me for Full Text 


\section{INTRODUCTION}

Chalazion is a common eyelid disease caused by plugged meibomian glands and chronic lipogranulomatous inflammation. It can affect any ages and may cause local eye symptoms such as irritation, inflammation and cosmetic disfigurement. ${ }^{1}$ Histopathological examination of chalazion reveals the presence of many neutrophils, lymphocytes, plasma cells and foreign body giant cells situated around cavities and clefts, which are assumed to be filled with lipid material derived from the meibomian gland. ${ }^{2}$ Different treatment options for chalazion include conservative management such as hot compresses and topical antibiotics, incision and curettage and intralesional steroid injection ${ }^{3}$. This study was done to compare all three methods of treatment of chalazion and find out the most effective method for treatment.

\section{MATERIALS AND METHOD}

$\mathrm{T}$ his is a prospective, randomized, interventional study conducted at Lumbini eye Institute and Research center (LEI), Bhairahawa. The study duration was from 15th March 2017 to 15th July 2017. All patients who come to department of oculoplasty for treatment of chalazion during the study period were included. Ethical approval by the Institutional Review Board was obtained. Those patient not willing to get enrolled were excluded.

Chalazion was diagnosed on the basis of history and clinical examination under slit lamp biomicroscopy. Any age groups from both the genders were included in the study. The purpose and benefits of the study were explained to all patients and written informed consent was obtained from all patients who were included in the study. Patients were explained about all three procedures and the procedure they choose was done.

\section{Conservative treatment:}

The patients were taught how to apply hot Compression (a clean cloth with a hot cooked ball of rice or a hardboiled egg or potato) to the affected lid for 5- 10 minutes and gently massaging the lid to encourage the chalazion to spontaneously drain. They were instructed to do this three times per day for 15 days followed by Tetracycline ointment massage to the lid.

\section{Incision and Curettage (I and C):}

A $1 \mathrm{ml}$ subconjunctival Injection with a 26 gauge needle was used to anesthetize the eyelid and the conjunctiva was anesthetized with a drop of $4 \%$ Xylocaine. The eyelid was everted and a lid clamp placed. A vertical incision through the tarsal plate into the meibomian gland was made and a curette inserted into the chalazion to break up the loculations and drain the chalazion. Tetracycline ointment was then applied to the treated eye and it was double padded. The patient was advised to keep the eye padded for at least 2 hours and apply Tetracycline ointment to apply to the affected eye at bedtimes for 15 days and chloramphenicol eye drops four times a day.

\section{Triamcinolone Acetonide (TA) Injection:}

Topical anesthesia (Xylocaine 4\%) eye drops were instilled in the affected eye before the injection. A volume of 0.1 to $0.3 \mathrm{ml}(40 \mathrm{mg} / \mathrm{ml})$ of Triamcinolone acetonide was injected intralesionally. The eyelids were inverted and the TA was injected transconjunctivally into the center of the lesion with a 27 gauge needle. When it was not possible to Evert the eyelids due to excessive swelling, the injection was given transcutaneously into the chalazion. No patching was required after the procedure. The patient was given Tetracycline ointment at night times to apply over the lesion.

All patients were followed up in the Out Patient Department after 2 weeks of treatment. The primary outcome measured was whether or not the chalazion had completely resolved. Complete resolution was defined as no longer a palpable lesion at the location of original chalazion. Patients who had complete resolution were discharged. If the chalazion had not completely resolved then the patient was offered retreatment.

1. Patient with previous Incision and curettage was offered re-treatment via Incision and curettage.

2. Patient with previous Triamcinolone acetonide Injection was offered a second Triamcinolone acetonide injection.

3. Patient with previous hot compression was offered Incision and curettage.

4. All patients were asked for follow up in 2 weeks duration and looked for complete resolution.

Data obtained were entered into Statistical Package for Social sciences (SPSS) 20 version. Statistical analysis was done. Results were entered in Microsoft excel for generation of table. Results obtained from study were then discussed with related literatures. A conclusion was drawn from the results. 


\section{RESULTS}

Out of 112 patients with chalazion that presented in Department of occuloplasty from 15th March to 15th July 2017, 47(42\%) were male and 65(58\%) were female (table 1). Male to Female ratio was 0.7:1.Left upper lid was involved in $41(36.6 \%)$, followed by the right upper lid in 36(32.1\%), right lower lid in 20(17.9\%), left lower lid was involved in 15(13.4\%).The mean age of the patients was 25.7years (SD 10.3).Patients age was divided into 5 categories out of which most presented in age group of $17-30=76(67.9 \%)$, while $14(12.5 \%)$ patients were in the age group of $<16$ years, $10(8.9 \%)$ were of age group 41-50, 9(8\%) were of age range 31-40 (table 1).

Table 1: Age Distribution of the patients

\begin{tabular}{c|c|c|l} 
Age (years) & Male & Female & \multicolumn{1}{|c}{ Total } \\
$\leq 16$ & 8 & 6 & $14(12.5 \%)$ \\
$17-30$ & 27 & 49 & $76(67.9 \%)$ \\
$31-40$ & 7 & 2 & $9(8 \%)$ \\
$41-50$ & 5 & 5 & $10(8.9 \%)$ \\
$>50$ & 0 & 3 & $3(2.6 \%)$ \\
\multicolumn{1}{c}{ Total } & 47 & 65 & $112(100 \%)$
\end{tabular}

Out of 27 patients in observation group, only $2(7 \%)$ showed complete resolution, $8(30 \%)$ showed a decrease in size and $17(63 \%)$ showed no change at 2 weeks follow up (Table 2). The secondprocedure as incision and curettage were done in 25/27 (92.6\%) with a complete resolution not requiring further procedure (Table 3 ).Triamcinolone acetonide was given in 32 cases out of which $20(63 \%)$ showed complete resolution $10(31 \%)$ showed a decrease in size and 2(6\%) showed no change (Table 2). The second procedure as repeat injection of Triamcinolone Acetonide was done in 11 cases (Table 3 ) out of which 7 required third procedure as incision and curettage.

Out of 53 cases enrolled in incision and curettage, $41(77.4 \%)$ were completely resolved, 10(18.9\%) showed the decrease in size, no change was seen in $2(3.8 \%)$ (Table 2) Second procedure was done in 11 cases with complete resolution (Table 3 ).

Table 2: Table eliciting response to different intervention in different sizes of chalazian at first Followup ( $\mathrm{P}$ value was calculated using chi square test(liklihood ratio):

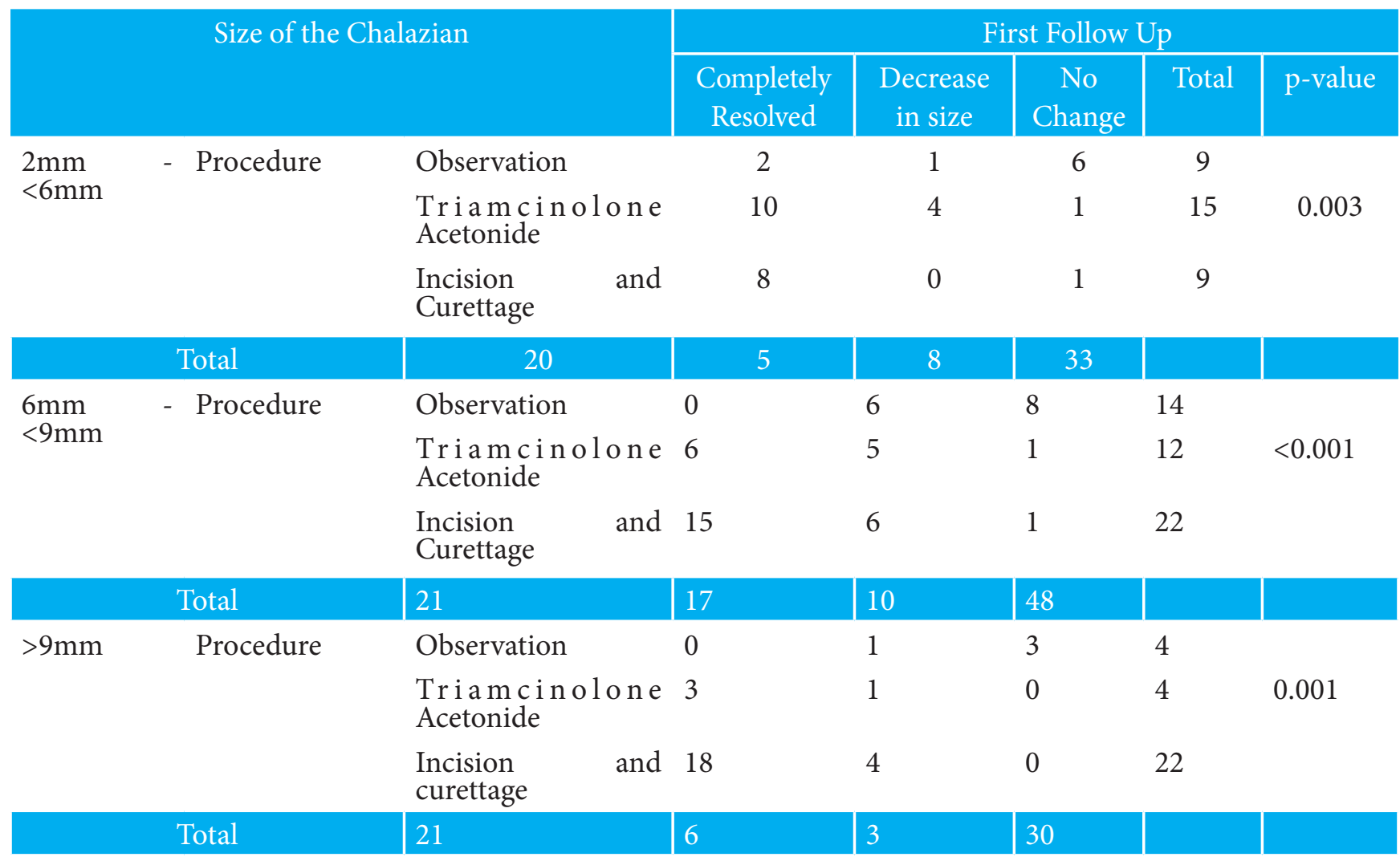




\begin{tabular}{|c|c|c|c|c|c|c|c|}
\hline \multirow[t]{3}{*}{ Total } & \multirow[t]{3}{*}{ Procedure } & Observation & 2 & 8 & 17 & 27 & \multirow{3}{*}{$<0.001$} \\
\hline & & $\begin{array}{l}\text { Triamcinolone } \\
\text { Acetonide }\end{array}$ & 19 & 10 & 2 & 31 & \\
\hline & & $\begin{array}{l}\text { Incision } \\
\text { Curettage }\end{array}$ & 41 & 10 & 2 & 53 & \\
\hline & Total & 62 & 28 & 21 & 111 & & \\
\hline
\end{tabular}

Table 3: Table eliciting a response to different intervention in different sizes of chalazia at Second Follow up:

\begin{tabular}{|c|c|c|c|c|c|}
\hline \multirow[t]{2}{*}{ Procedure } & & \multicolumn{3}{|c|}{ Second. Procedure } & \multirow[t]{2}{*}{ Total } \\
\hline & & $\begin{array}{l}\text { Triamcinolone } \\
\text { Acetonide }\end{array}$ & $\begin{array}{l}\text { Incision and } \\
\text { Curettage }\end{array}$ & Not required & \\
\hline \multirow[t]{3}{*}{ Procedure } & Observation & $0(0.0 \%)$ & $25(92.6 \%)$ & $2(7.4 \%)$ & $27(100 \%)$ \\
\hline & $\begin{array}{l}\text { Triamcinolone } \\
\text { Acetonide }\end{array}$ & $11(34.4 \%)$ & $1(3.1 \%)$ & $20(62.5 \%)$ & $32(100 \%)$ \\
\hline & $\begin{array}{l}\text { Incision and } \\
\text { Curettage }\end{array}$ & $0(0.0 \%)$ & $11(20.8 \%)$ & $42(79.2 \%)$ & $53(100 \%)$ \\
\hline & tal & $11(9.8 \%)$ & $37(33 \%)$ & $64(57.1 \%)$ & $112(100 \%)$ \\
\hline
\end{tabular}

Table 4: Pearsons Correlation for different intervention for different sizes of Chalazia (Cummulatively)

\begin{tabular}{llllll} 
& & \multicolumn{5}{c}{ Size } & & \\
\multirow{3}{*}{ Completely resolved } & 2 to $6 \mathrm{~mm}(\%)$ & 6 to $9 \mathrm{~mm}(\%)$ & $>9(\%)$ & $\mathrm{p}$-value \\
& Observation & -0.3 & -0.56 & -0.93 & \\
& Tricort & 0.59 & 0.39 & 0.22 & \\
Decrease in size & I and C & 0.91 & 0.93 & 0.89 & \\
& Observation & 0.2 & 0.12 & -0.21 & \\
\multirow{2}{*}{ No Change } & Tricort & 0.68 & 0.42 & 0.31 & $\mathrm{p}<0.05$ \\
& I and C & 0.96 & 0.93 & 0.87 & \\
& Observation & 0.66 & 0.89 & 0.93 & \\
& Tricort & -0.79 & -0.55 & -0.29 & \\
\hline
\end{tabular}

We correlated the different intervention that were performed at any stage during the study according the size of the lesion at baseline using the pearson's correlation coefficient. We found that Incision and Curettage remained superior for any size followed by Intralesional Triamcinolone. Observation did show tendency for some lesions specially 2 to $6 \mathrm{~mm}$ to decrease in size but showed a negative tendency to complete resolve and strong tendency to remain as it is for the lesions of all the sizes. The details of the correlation can be found in Table 4 .

\section{DISCUSSION}

chalazion is a localized, lipogranulomatous lesion of the eyelid. It is an inflammatory process, caused by an - obstruction of the sebaceous glands of the eyelid (meibomian and Zeiss) from inflammatory disease (eg, acne rosacea), infection (eg, seborrheic dermatitis), or neoplasm (eg: sebaceous gland carcinoma or Merkel cell carcinoma). ${ }^{4}$ A chalazion is the most common inflammatory lesion of the eyelids. ${ }^{3}$ Patients often present with a persistent (often more than 2 weeks), initially painless nodule in the eyelid. The lesion may grow and distort the lid causing discomfort in the surrounding tissue. ${ }^{5}$ 
Incidence of chalazion in our institute is $0.66 \%$ which is similar to study done by TO Otulana et al which shows incidence of $0.7 \% 6$. In our study female $65(58 \%)$ were affected more than male $47(42 \%)$, as found in previous studies. ${ }^{6,7}$ Chalazion occurs across all ages, it may cluster at puberty but it is less prevalent among the elderly ${ }^{6}$. Similar to other studies maximum incidence was seen in age group 17-30(67.9\%) because of higher level of androgenic hormones which increases seabumviscosity. ${ }^{3,6,7}$ Chalazion occurs more often on the upper eyelid than the lower one for anatomical reasons6. Similarly in our study upper lid were more involved then lower lid Left Upper Lid 41(36.6\%) and Right Upper Lid 36(32.1\%) because the number of meibomian glands are higher in upper lid. ${ }^{7}$

\section{CONCLUSION}

A lthough Incision and Curettage remains the gold standard for treatment for chalazion, there remains a debate among ophthalmologists to treat it in more conservative fashion or with Intralesional Triamcinolone Acetonide. Our study showed that Incision and Curettage still remains superior to other procedures for any given size of chalazia with virtually no further procedures required. Intralesional TA may also be tried smaller sized chalazia $(2-6 \mathrm{~mm})$ for which observatrion has failed to show any improvement. It may also be uselful in larger sized chalazia but multiple injections maybe required and may mostly only show decrease in size without complete resolution. Our study highlights observation may only be tried if the chalazia is small $(2-6 \mathrm{~mm})$ initially. If the size of the chalazia are larger than these dimensions at presentation or show/ minimal change at followup, observation alone is not likely to produce resolution.

\section{REFERENCES}

1. Ben SGJ, Huang L, Nakra T, Schwarcz RM, McCann JD, Goldberg RA. Intralesional triamcinolone acetonide injection for primary and recurrent chalazia: is it really effective? Ophthalmology 2005;112(5):913-7.https://doi.org/10.1016/j. ophtha.2004.11.037 [CrossRef] [GoogleScholar] [PubMed]

2. Jasna Pavičić-Astaloš J, Iveković R, Knežević $T$, Krolo I, Novak-Lauš K, Tedeschi-Reiner E, et al. Intralesional triamcinolone acetonide injection for chalazion. Acta Clin Croat 2010;49:43-48. [GoogleScholar]
3. Tahir MZ, Rehman M, Ahmad I, Aqbal A, Hussain I. Effectiveness of Intralesional Triamcinolone Acetonide in the treatment of Chalazion. Pak J Opthalmol 2015;31(1):9-14. [CrossRef] [GoogleScholar]

4. Skorin, L. Hordeolum and chalazion treatment: the full gamut. Optometry Today [Internet]. 2002 [cited 2019 Dec 23]; 25-27. Link

5. Kuiper J, Vislisel JM, Scruggs BA, Hock LE, Shriver EM. Chalazion: acute presentation and recurrence in a 4-year-old female. EyeRounds.org 2014;25:12-18. [CrossRef] [GoogleScholar]

6. Otulana TO, Bodunde OT, Ajibode HA. Chalazion, a benign eyelid tumour: the sagamu experience. Nigerian Journal of Ophthalmology 2008;16(2):3335. https://doi.org/10.4314/njo.v16i2.46740 [CrossRef] [GoogleScholar]

7. Kumar J, Pathak AK, Verma A, Dwivedi S. Study of incidence and risk factors of Chalazion in Bundelkhand region. IOSR-Journal of Dental and Medical Sciences 2017; 16(5):5-8.https://doi.org/10.9790/0853$\underline{1605080508}$ [CrossRef] [GoogleScholar]

8. Goawalla A, Lee V. A prospective randomized treatment study comparing three treatment options for chalazia: triamcinolone acetonide injections, incision and curettage and treatment with hot compresses. Clinical and Experimental Ophthalmology 2007;35(8):706712.https://doi.org/10.1111/j.1442-9071.2007.01617.x [CrossRef] [GoogleScholar] [PubMed]

9. Lee JWY, Yau GSK, Wong MYY, Yuen CYF. A Comparison of Intralesional Triamcinolone Acetonide Injection for Primary Chalazion in Children and Adults. The Scientific World Journal 2014;15:41372933.https://doi.org/10.1155/2014/413729 [CrossRef] [GoogleScholar] 